\title{
Observations on a trypanosomatid flagellate in a flea, Peromyscopsylla silvatica spectabilis
}

\author{
by D. H. MOLYNEUX and R. W. ASHFORD \\ Department of Parasitology, Liverpool School of Tropical Medicine, Pembroke Place, \\ Liverpool L3 $5 Q A$, England
}

\section{Summary.}

The method of attachment of a trypanosomatid parasite to the cuticular epithelium of the hindgut of a flea Peromyscopsylla silvatica spectabilis by a desmosome-like structure is described; the flagella are modified and have enlarged intraflagellar areas which occupy the whole surface area of the gut, including clefts and folds of the epithelium. Unusual features of the parasite itself include a very much reduced flagellar pocket and pellicular microtubules which are made up of doublets and triplets. The problems of differentiation and characterisation of monogenetic insect flagellates are discussed in the light of these findings.

\section{Résumé.}

Observations sur un Trypanosomatidae Flagellé de la Puce, Peromyscopsylla sylvatica spectabilis.

Le mode d'attachement d'un parasite de la famille des Trypanosomatidae à l'épithélium intestinale postérieur de Peromyscopsylla silvatica spectabilis (Siphonaptera) est discuté. Cet attachement est réalisé par un «desmosome ». Les flagelles sont modifiées et leurs parties intraflagellaires agrandies. Les flagelles couvrent entièrement la surface de l'intestin. Le parasite a une petite poche flagellaire et les microtubules pelliculaires sont quelquefois organisés en doublets ou triplets. Les problèmes de différenciation et de taxonomie des flagellés d'insectes sont discutés. 
Ultrastructural studies on the relationship between monogenetic flagellates and their insect hosts have been made recently (Brooker, 1971; Bailey and Brooks, 1972; Brun, 1974). The mecanism of attachment displayed by these flagellates is similar to that found in trypanosomes and Leishmania in their vectors (Molyneux, 1969; Vickerman, 1973; Killick-Kendrick, Molyneux and Ashford, 1974; Molyneux, 1975). When the parasites are attached to cuticular epithelium, junctional complexes known as hemidesmosomes are formed within the flagellar membrane of the parasite and the intraflagellar area is highly expanded. Parasites in midgut, or Glossina salivary glands, where the epithelia have microvilli, have unmodified flagella inserted between the microvilli, with or without hemidesmosomes being formed (Steiger, 1973; KillickKendrick, et al., 1974; Molyneux, 1975). Dissection of a flea Peromyscopsylla silvatica spectabilis revealed flagellates attached to the hindgut and the hindgut triangle. Because the method of attachment of trypanosomatids in this site in fleas is not known the material was fixed and examined with the electron microscope.

\section{Materials and methods.}

The flea, Peromyscopsylla silvatica spectabilis, was collected from a field vole Microtus agrestis, which had also been associated with Clethrionomys glareolus, the bank-vole. These voles harboured trypanosomes of the subgenus Herpetosoma, presumably $T$. (H.) microti and $T$. (H.) evotomys respectively. The flea was dissected to observe stages of these trypanosomes (Molyneux, 1970). Flagellates were observed during the dissection in physiological saline in the hindgut and hindgut triangle and it was thought that these parasites might be the stages in the life-cycle of the trypanosomes. The gut was immediately fixed in $3 \%$ glutaraldehyde in $0.2 \mathrm{M}$ cacodylate buffer and processed for electron microscopy as described by Killick-Kendrick et al. (1974).

\section{Results.}

Observations on the ultrastructure of the flagellate in the hindgut and hindgut triangle both as attached forms and apparently free in the lumen failed to reveal any evidence of the presence of metacyclic trypomastigotes. The presence of these forms would have indicated that the flagellates were stages of a Herpetosoma trypanosome. It was concluded therefore that the parasites observed were more likely to be stages of a monogenetic flagellate which parasitises fleas (Wallace, 1966) than a trypanosome; the presence of flagellates in Peromyscopsylla silvatica spectabilis is a new host record.

The flagellates were attached to the cuticular epithelium of the hindgut by osmiophilic plaques on the inner leaflet of the flagellar membrane (fig. 5, 6, 8). The flagellar membrane was separated by a distance of $20-25 \mathrm{~nm}$ from a membrane covering the cuticle lining of the gut (fig. 5, 6). This membrane had a dense band adja- 

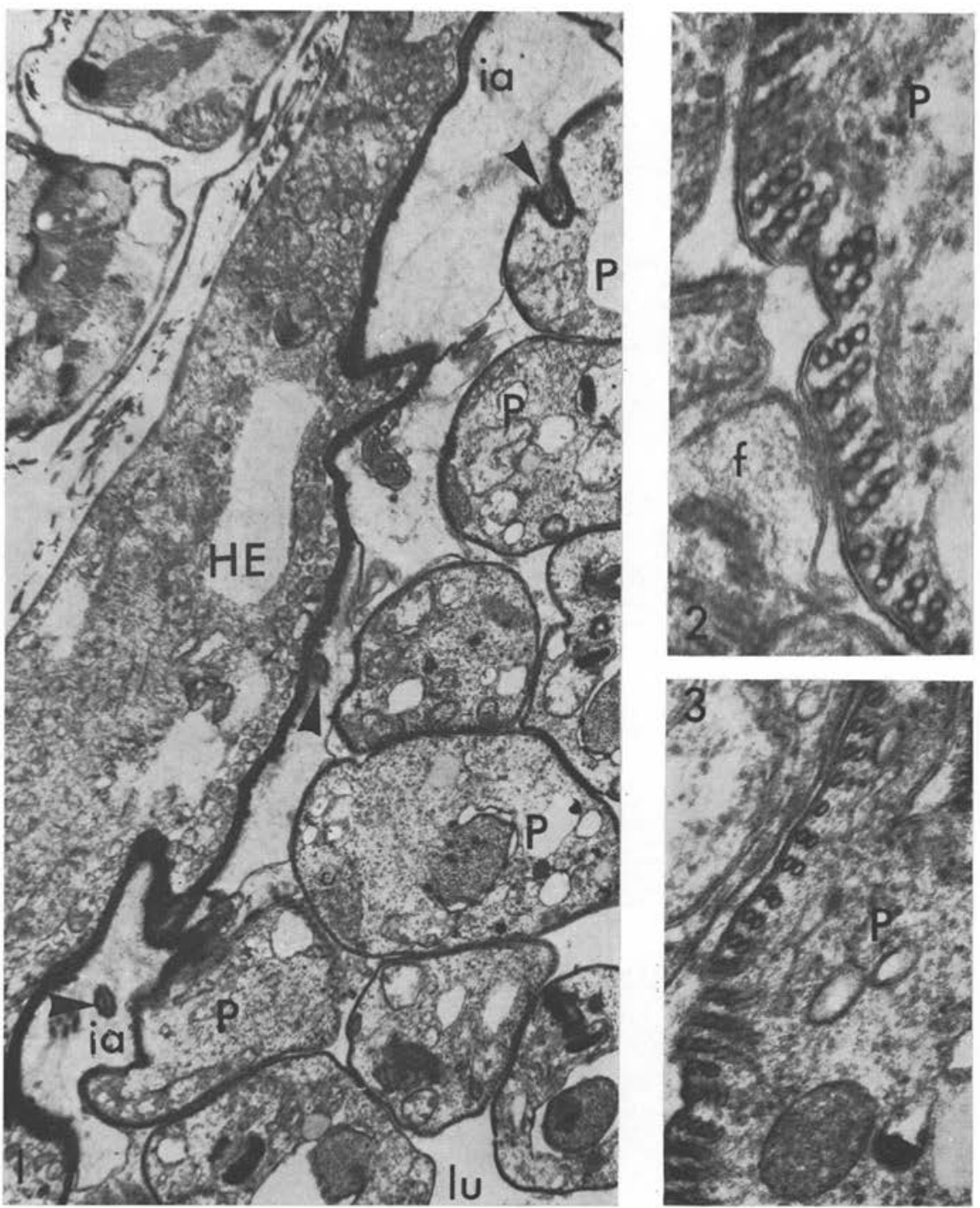

FIg. 1. - Section of flea hindgut epithelium (HE) showing attachment of flagellate parasites (P) to epithelium by their flagella. Expanded intraflagellar area (ia) and axonemes within these regions arrowed $(\times 10,000)$.

FIG. 2 and 3. - Section of plasmalemma of parasite showing some of the subpellicular microtubules made up of triplets and doublets (fig. $2 \times 120,000-$ fig. $3 \times 60,000$ ) 

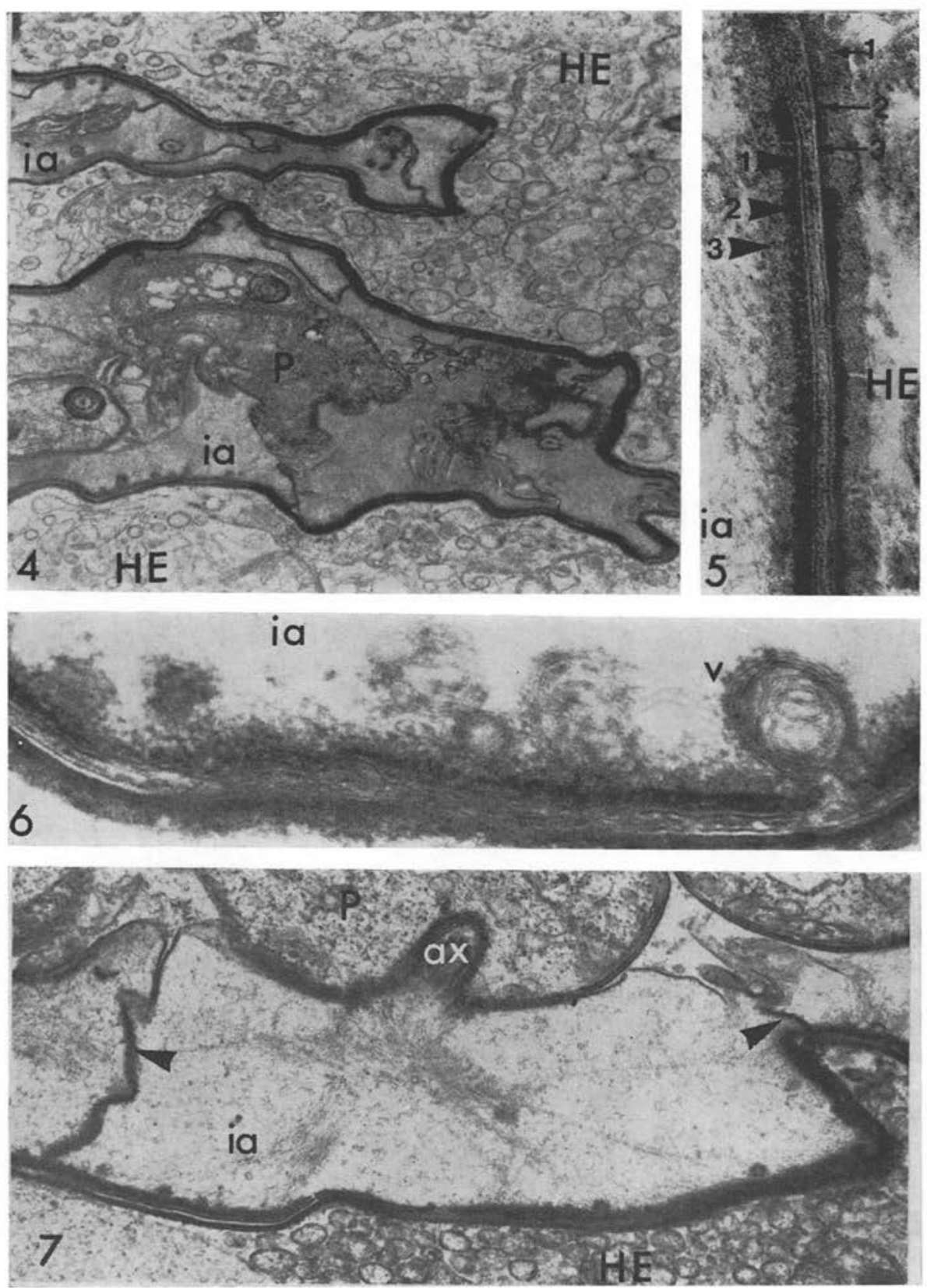

FIG. 4 à 7 
cent to the inner band of the membrane (fig. 5, 6). This mirror image appearance of the apposed surfaces with material between suggests that attachment at least of some of these flagellates is by a desmosome-like junction rather than by a hemidesmosome which is seen in other systems of this type. Although no controls are available in the form of unparasitised epithelium, it is possible that the presence of the fla. gellate has provoked a host reaction. The plaques on the flagellar side were made up of two regions, both of which run parallel to the fagellar membrane: a more dense distal osmiophilic zone of $30-35 \mathrm{~nm}$ in width and a second proximal band of more diffuse material, $30-40 \mathrm{~nm}$ wide. This latter zone was associated with strands of indefinite structure which were distributed throughout the enormously expanded intraflagellar areas (fig. 7, 8). Within the flagellar sheath, vesicles were commonly found and pinocytotic-like intuckings of the membrane in contact with the host epithelium were observed (fig. 6, 8). The axonemes of the attached flagellates were short and terminated about $0.5 \mu \mathrm{m}$ from desmosomal plaques (fig. 8). No multiple axonemal structures have been observed (Molyneux, 1969; Killick-Kendrick et al., 1974; Brun, 1974). The parasites, which occupy the whole of the gut surface, were found to fill any cleft or fold in the hindgut epithelium (fig. 4, 7). Flagellar-flagellar desmosomes between adjacent flagellates were also found.

The flagellates themselves have several features which are of interest and which combine to make generic identification difficult. The flagellar pocket or reservoir is almost obliterated in the attached parasites (fig. 8, 9). It would seem that the opportunity for pinocytosis no longer exists in this region of the parasite. The parasites' morphological configuration is difficult to assess as the flagellum emerges from the anterior end of the parasite (fig. 8) with apparent symmetry. However, because of the large area of contact between the parasite membrane and flagellar membrane, an « undulating membrane » type of attachment zone mediated by maculae adherentes was observed as the flagellum emerges from the minute reservoir (fig. 8).

Some parasites in this site exhibited doublets and triplets of subpellicular microtubules (fig. 2, 3, 10). The individual tubules within the groups were the same

FIG. 4. - Section through hindgut of flea showing parasites and the modified flagella filling clefts and folds of epithelial wall $(\times 10,000)$

FIG. 5. - High power electron micrograph of section through junctional complex, between flagellar membrane (large arrow 1) and apposed membrane (small arrow 3). HE is hindgut side of junction; ia is intraflagellar area of the attached flagellum. Large arrow 2 indicates dense distal band of « desmosome». Large arrow 3 less dense proximal band. Small arrows 1 and 2 indicate desmosomal appearance on host side of junction $(\times 120,000)$.

FIG. 6. - Showing junction between a flagellum and hindgut cuticle with vesicular intuckings of flagellar membrane $(v)(\times 120,000)$.

FIG. 7. - Showing extent of expansion of flagellum of attached flagellate. Arrows indicate junctions between flagellar membrane of adjacent flagella $(\times 20,000)$. 


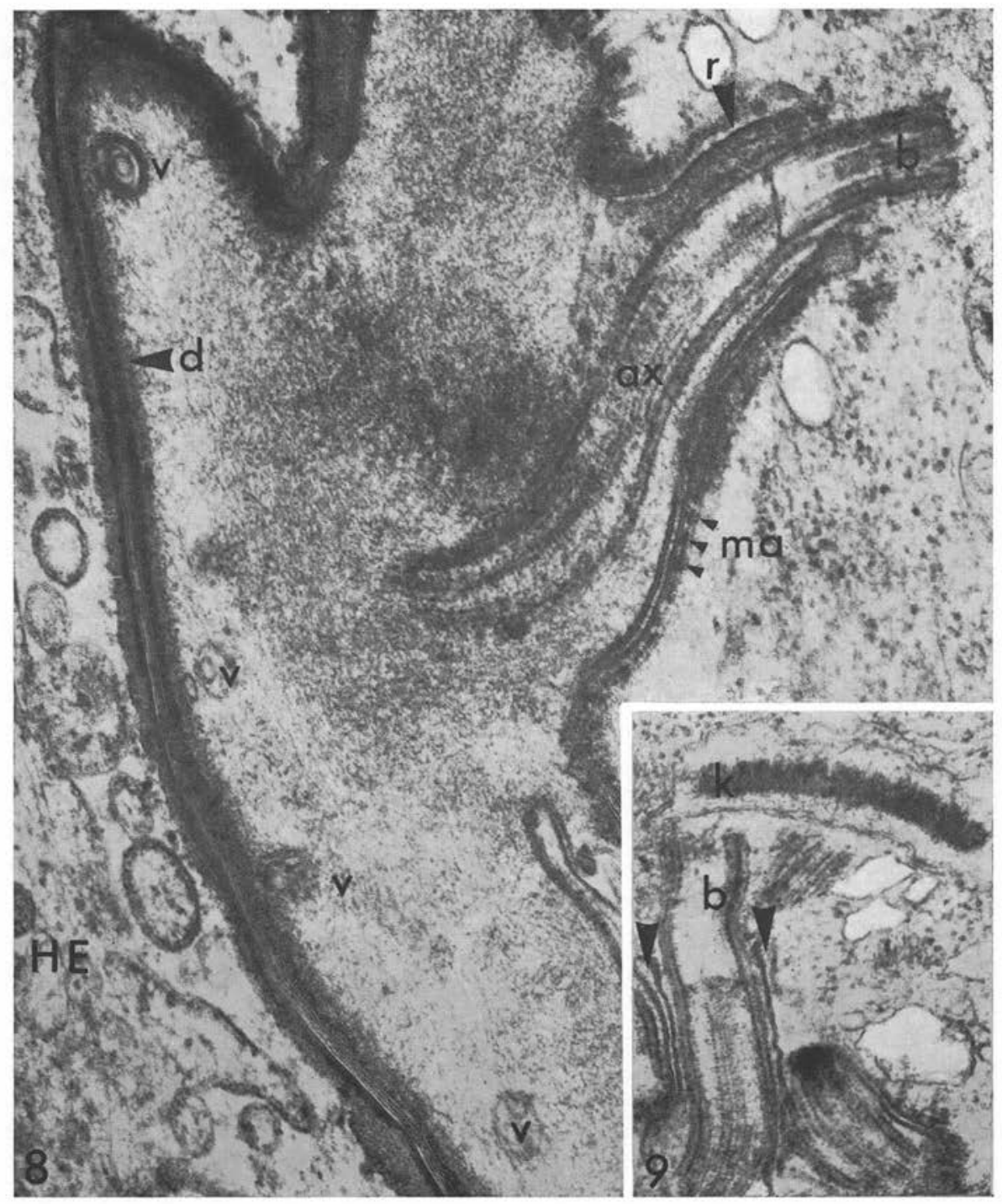

FIG. 8. - Micrograph of attached flagellate showing basal body (b) and axoneme (ax) of organism; reduced reservoir (r) is arrowed. Vesicles are seen associated with flagellar membrane. «Desmosome-like» (d) junction is arrowed. Small arrows show maculae adherentes (ma) of undulating membrane type attachment between parasite and flagellum $(\times 60,000)$.

FIG. 9. - Showing structure of the kinetoplast and basal body of the flea flagellate; arrows mark points of transformation of flagellar-plasma membrane at base of \& reservoir » $(\times 50,000)$. 
diameter as normally found in trypanosomatids but the individual tubules were attached to each other (fig. 2, 3, 10), and occurred at a variety of angles to the plasmalemma; groups of polytubules usually ran parallel although on one occasion, it was observed that the proximal tubules of two triplets were in contact resulting in a group of six tubules.

The kinetoplast of the flagellate exhibited an unusually dense appearance and a poorly defined periphery (fig. 9). The fibres of the organelle could be determined more easily if plates were printed with reduced exposure and this resulted in the DNA appearing as a band of fine fibres. This appearance which is unusual in kinetoplastid flagellates, may have been induced by fixation techniques.

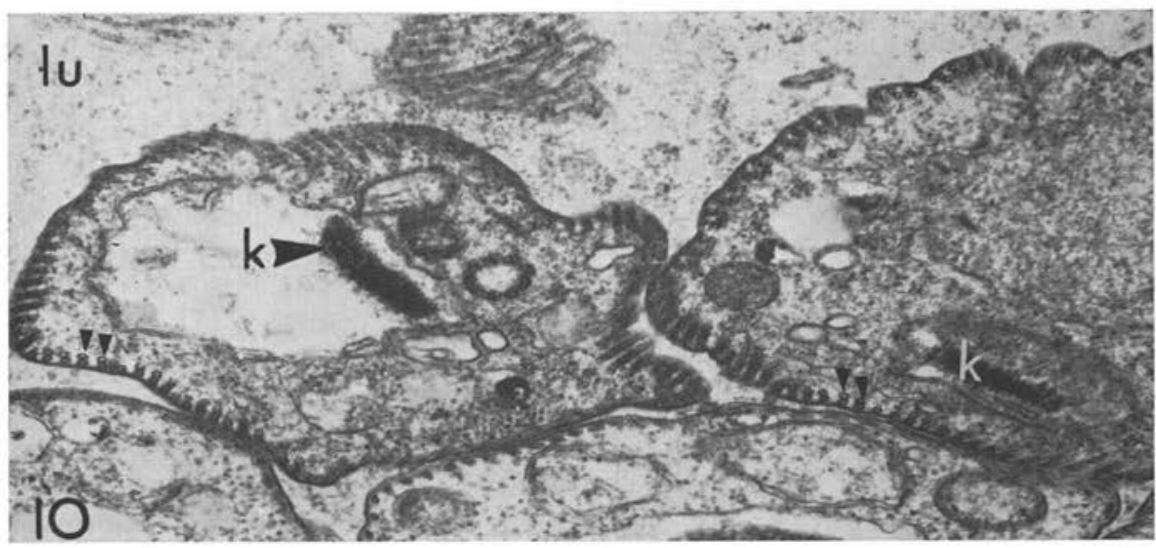

FIG. 10. - Showing kinetoplastid nature of the organism and presence of doublet microtubules in two parasites $(\times 30,000)$.

\section{Discussion.}

The method of attachment of a flagellate found in the hindgut of Peromyscopsylla silvatica spectabilis differs from that observed in other species of trypanosomatids attached to insect gut epithelia in that attachment may be mediated through a desmosome-like junction indicated by a contribution from the host tissue to the attachment zone rather than by a hemidesmosome where only the parasite's flagellar structure is modified (Molyneux, 1969; Brooker, 1971; Vickerman, 1973; Steiger, 1973; Killick-Kendrick et al., 1974; Brun, 1974; Molyneux, 1975). This is the first occasion on which flagellate attachment has been described in the hindgut of Siphonaptera although Molyneux (1969) reported the attachment of T. lewisi in the rectum of a flea, Nosopsyllus fasciatus. The parasites in the hindgut colonise the whole of the available surface, resulting in the gut surface not being exposed to the lumen. This must impede the function of the hindgut severely as an absorptive sur- 
face. The presence of this flagellate may also prevent establishment of other flagellate species if the habitat availabe for establishment is fully utilised.

Other observations on this flagellate have not enabled us to determine its identity. We have concluded that as no metacyclic trypanosomes have been seen, the parasite is not likely to belong to the genus Trypanosoma. The remaining genera to which this organism could belong are Crithidia, Blastocrithidia, Herpetomonas and Leptomonas. The organism seems to be modified completely for attachment in its natural host to the extent that none of the structural features characterising known insect flagellate genera can be clearly identified in this parasite (Wallace, 1966). The identification of parasites from smears or sections of insect guts is not satisfactory as the spatial relationships of the organelles cannot always be determined. In culture, the parasites may be modified completely due to the artificial environment in which they are found and a possibility of a mixed infection being present at isolation can only be ruled out by cloning. The ability of parasites to change their shape in relation to insect gut structure and because of the difference in morphology between host and cultures (Killick-Kendrick et al., 1974), we suggest that techniques of biochemical taxonomy allied to ultrastructural studies of flagellates in natural hosts only can determine the true relationships of the flagellate genera. The difficulty in deciding on the configuration of a parasite in smears has been emphasised, i.e, promastigote or epimastigote, or choanomastigote; opisthomastigote or trypomastigote. In the case discussed in this paper, the kinetoplast is in a position similar to that observed in promastigotes of Leishmania but there is evidence of an undulating membrane type structure; the reservoir is completely reduced and the axoneme approaches the size seen in amastigotes of Leishmania parasites in tissue, referred to as micromastigotes by Jadin (1971). The flagellum itself is enormously expanded with the axoneme occupying only a fraction of the total volume. Stained preparation of this material would not have revealed the true nature of this parasite or any details of the host parasite relationship. The unusual finding of triplet and doublet subpellicular microtubules cannot yet be explained. It is possible that they represent changes necessary for the formation of resistant stages or « cysts » required for transmission of this flagellate in the flea faeces and subsequent survival in deposited faeces and flea larvae.

The monogenetic flagellates show great variation and overlap in morphology and may only infrequently display supposedly generic characteristics when viewed with the light microscope. We, therefore, feel a reappraisal of the criteria for the identification of this group is required in the light of recent advances in biochemical taxonomic techniques (Newton and Burnett, 1972; Kilgour and Godfrey, 1973; Chance, Peters and Shchory, 1974; Ebert, 1973, 1974; Gardener, Chance and Peters, 1974).

\section{ACKNOWLEDGEMENTS}

We are grateful to Professor W. Peters for his helpful critiscism of the manuscript and to the World Health Organisation and the Wellcome Trust for financial assistance towards the cost of the work. 
Key to lettering of figures

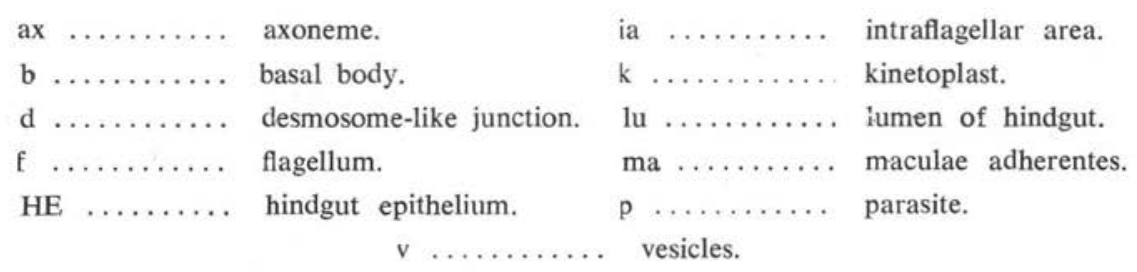

\section{Bibliography}

BaILeY (C. H.) et BrooKs (W. M.), 1972. - Histological observations on larvae of the eye gnat, Hippelates pusio (Diptera: Chloropidae), infected with the flagellate Herpetomonas muscarum. J. Invert. Pathol., 19, 342-353.

BrooKer (B.), 1971. - Flagellar attachment and detachment of Crithidia fasciculata to the gut wall of Anopheles gambiae. Protoplasma, 73, 191-202.

BRUN (R.), 1974. - Ultrastruktur und Zyklus von Herpetosoma muscarum « Herpetosoma mirabilis» und Crithidia luciliae in Chrysomyia chloropyga. Acta tropica, 31, 217-290.

Chance (M. L.), Peters (W.) and Shchory (L.), 1974. - Biochemical taxonomy of Leishmania. I. Observations on DNA. Ann. trop. Med. Parasit., 68, 307-316.

EberT (F.), 1973. - Charakterisierung von Leishmania donovani Stämmen mit der Disk-Elektrophorese. Z. Tropenmed. Parasit., 24, 517-524.

EBERT (F.), 1974. - Elektrophoretische Untersuchungen an Leishmania tropica Stämmen. Z. Tropenmed. Parasit., 25, 49-53.

Gardener (P. J.), Chance (M. L.) and Peters (W.), 1974 - - Biochemical taxonomy of Leishmania. II. Electrophoretic variation of malate dehydrogenase. Ann. trop. Med. Parasit., 68, 317-325.

JADIN (J.-M.), 1971. - Cytologie et cytophysiologie des Trypanosomatidae. Acta Zool. Pathol. Antverp., 53, 3-168.

Kilgour (V.) et Godfrey (D. G.), 1973. - Species-characteristic isoenzymes of two aminotransferases in trypanosomes. Nature New Biology, 244, 69-70.

Killick-Kendrick (R.), Molyneux (D. H.) and Ashford (R. W.), 1974. - Leishmania in phlebotomid sandflies. I. Modifications of the flagellum associated with attachment to the midgut and œsophageal valve of the sandfly. Proc. R. Soc. Lond. B., $187,409-419$.

Molyneux (D. H.), 1969. - The fine structure of the epimastigote forms of Trypanosoma lewisi in the rectum of the flea Nosopsyllus fasciatus. Parasitol., 59, 55-66.

Molyneux (D.-H), 1970. - Developmental patterns in Trypanosomes of the subgenus Herpetosoma. Ann. Soc. belge Med. trop., 50, 229-238. 
MolyneuX (D.-H.), 1975. - Trypanosoma (Megatrypanum) melophagium : Modes of attachment of parasites to mid-gut, hind-gut and rectum of the sheep ked, Melophagus ovinus. Acta Tropica, 32, 65-74.

Newton (B.) and Burnett (J. K.), 1972. - DNA of Kinetoplastidae : A comparative study. In: Comparative Biochemistry of Parasites, ed. Van den Bossche. Academic Press, Publ., London, 516 p.

STEIGER (R.F.), 1973. - On the ultrastructure of Trypanosoma (Trypanozoon) brucei in the course of its life cycle and some related aspects. Acta tropica, 30, 64-168.

Wali.ace (F. G.), 1966. - The trypanosomatid parasites of insects and arachnids. Expl. Parasit., 18, 124-193.

Vickerman (K.), 1973. - The mode of attachment of Trypanosoma vivax in the proboscis of the tsetse fly Glossina fuscipes: an ultrastructural study of the epimastigote stage of the trypanosome. J. Protozool., 20, 394-404. 